\title{
Mango (Mangifera indica) Aroma Discriminate Cultivars and Ripeness Stages
}

\author{
Paulo R. R. Mesquita, ${ }^{\circledR *, a, b}$ Laiane C. Pena, ${ }^{b}$ Fábio N. dos Santos, ${ }^{\circ}$ Camilo C. de Oliveira, ${ }^{b}$ \\ Jairo T. Magalhães-Junior, ${ }^{d}$ Antonio S. Nascimento ${ }^{e}$ and Frederico M. Rodrigues ${ }^{a, b}$ \\ ${ }^{a}$ Centro Tecnológico Agropecuário do Estado da Bahia (CETAB), 40170-110 Salvador-BA, Brazil \\ ${ }^{b}$ Programa de Pós-Graduação em Desenvolvimento Regional e Meio Ambiente, \\ Faculdade Maria Milza (FAMAM), 44350-000 Governador Mangabeira-BA, Brazil \\ 'Laboratório ThoMSon de Espectrometria de Massas, Instituto de Química, \\ Universidade Estadual de Campinas, 13083-970 Campinas-SP, Brazil \\ ${ }^{d}$ Centro Multidisciplinar de Barra, Universidade Federal do Oeste da Bahia (UFOB), \\ 47100-000 Barra-BA, Brazil \\ ${ }^{e}$ Embrapa Mandioca e Fruticultura, 44380-000 Cruz das Almas-BA, Brazil
}

\begin{abstract}
Mango (Mangifera indica) has many nutritional attributes that stimulate its consumption, such as sweetness, balanced acidity and intense fruity aroma. In this study, it was demonstrated that both the variety and ripening stage have a significant impact on the aroma of mango. The volatile compound profile of "Tommy Atkins", "palmer", "espada" and "Carlota" varieties in green and ripe stages were characterized by headspace solid-phase microextraction gas chromatography mass spectrometry (HS-SPME/GC-MS). Thirty-three volatile compounds were identified, 30 from "Tommy Atkins", 29 from "espada", 25 from "palmer" and 10 from the "Carlota" variety. The major compounds were monoterpene and sesquiterpene hydrocarbons, regardless of the degree of maturity. However, the oxygenated monoterpenes, esters and lactones were also identified as minor compounds. $\delta$-3-Carene terpene is the most abundant in the varieties "Tommy Atkins" and "palmer", $\alpha$-terpinolene is the most abundant in the cv. "espada", and myrcene in cv. "Carlota". The profile's aroma obtained by HS-SPME/GC-MS associated with multivariate data analysis lead to discrimination of four mango varieties in green and ripeness stages. Therefore, the volatile compounds markers of fruit maturation identified in this study can be used to increase the efficiency of mango sorting to improve quality control and meet the consumer market requirements.
\end{abstract}

Keywords: Mangifera indica L., volatile compounds, SPME, chemometrics

\section{Introduction}

Mango (Mangifera indica L.) is a fruit rich in fiber, vitamin $\mathrm{C}$ and $\beta$-carotene that comprises approximately $80 \%$ of water and up to $20 \%$ of sugars. ${ }^{1}$ Its flavor is an important characteristic that contributes to its consumption and popularity. ${ }^{2}$

Brazil is the seventh-largest mango producer in the world. Not to mention this product is considered the top source of revenue from fresh fruit exports, with US\$ 177.3 million generated from the sale of 170.5 thousand tons in $2018 .^{3}$ The cultivars "Tommy Atkins", "haden", "palmer", "Kent and Keitt" are mainly grown for exportation, ${ }^{4}$ while the

*e-mail: prrmesquita@gmail.com cultivars "espada", "rosa" and "Carlota" are sold in the national consumer market. ${ }^{5}$

Mango fruit is mostly consumed fresh, but can also be used to prepare juice, jam and frozen pulp. The fresh fruit appearance is a relevant factor in its commercialization since consumers prefer red mangoes with perfect peels. Due to its fragility and perishability, it is difficult to maintain its quality after harvesting which limits the expansion of exports. ${ }^{6}$ High-quality mangoes generally have low fiber content, strong sweet taste, balanced acidity and an intense fruity aroma with low terpene notes.

The volatile organic compounds (VOCs) are responsible for the fruit aroma which depends mainly on the kind of cultivar among many other factors. ${ }^{2}$ Some studies have been carried out to determine the VOCs profile of different 
mango cultivars and led to the identification of more than 300 compounds including esters, aldehydes, ketones, aliphatic alcohols, $\gamma$ and $\delta$-lactones, and mono- and sesquiterpenes. ${ }^{7}$ It has also been assessed that variety, ${ }^{7-9}$ ripening stage, ${ }^{10,11}$ geographic origin, ${ }^{12}$ fruit part, ${ }^{13,14}$ treatment after harvesting,,${ }^{15}$ and fruit processing ${ }^{16}$ affect the volatile compound profile of fresh mangoes. Despite the contribution of the abovementioned studies, the VOCs profile of many mango varieties has not been completely assessed yet. Their identification is relevant since VOCs can be associated with pest insects, particularly mango fruit flies, in cultivated areas.

Because of the extraction efficiency of low volatility compounds, the most applied mango VOCs extraction methods are solvent extraction, ${ }^{17,18}$ simultaneous distillation and extraction (SDE), ${ }^{19,20}$ and hydro-distillation. ${ }^{21}$ However, these methods can produce artifacts due to the degradation of thermolabile compounds. Therefore, headspace solid-phase microextraction (HS-SPME) is the recommended volatile compound extraction method, and is based on the interaction of chemical analytes with a solid phase that may have different film polarity, thickness and porosity. ${ }^{22}$ On the other hand, SPME allows desorption followed by direct injection of analytes in the gas chromatography mass spectrometry (GC-MS) turning the analysis quick and handy.

These characteristics explain why SPME is a widely used technique for volatile compounds profile analysis in various vegetal matrixes, such as pepper (Capsicum chinense sp.), ${ }^{23}$ Plectranthus ornatus callus ${ }^{24}$ Mikania glomerata Sprengel leaves, ${ }^{25}$ acerola fruits, ${ }^{26}$ as well as mango. ${ }^{21,27,28}$ In this study, the objective was to differentiate "Tommy Atkins", "palmer", "espada" and "Carlota" cultivars and their ripeness stages based on the profiles of the volatile organic compounds analyzed by HS-SPME/GC-MS.

\section{Experimental}

\section{Materials}

The standard solutions of $n$-alkanes $\mathrm{C}_{8}-\mathrm{C}_{24}$, ethyl butanoate, $\alpha$-pinene, $\beta$-myrcene, $\alpha$-phellandrene, $\delta$-3-carene, D-limonene, $\beta$-ocimene, $\alpha$-terpinolene, ethyl octanoate, and trans- $\beta$-caryophyllene were purchased from Sigma-Aldrich, (St. Louis, USA). The volatile compounds were extracted and concentrated in carboxen/polydimethylsiloxane (CAR/ PDMS) SPME fiber $(75 \mu \mathrm{m})$, using the SPME holder for manual sampling (Supelco, Bellefonte, USA).

\section{Fruits}

Physically uniform green mango fruits, without any visible signs of disease, were purchased from the Active
Bank of Mango Germoplasm (varieties "Carlota" and "espada") of Embrapa Mandioca e Fruticultura (Cruz das Almas) and farms of the municipality of Juazeiro (varieties "Tommy Atkins" and "palmer"), both cities are located in the state of Bahia (Brazil). Sampling was carried out between December 2016 and May 2017. Four fruits with peduncles from each variety were collected in the orchards and transported in closed plastic bags to the laboratory, where they were washed in tap water and stored at room temperature. The fruit mass in the green stage ranged from 150.0 to $420.0 \mathrm{~g}$. These samples were analyzed in their green stage and after natural ripening to maturity at room temperature. Ripening stages were recognized through texture and color changes in the fruit peel, using the maturity stage scale developed for the "Tommy Atkins" mango. ${ }^{29}$ Following this maturation scale, mangoes were used with the shell almost entirely green (level 1 or 2 ) and the shell predominantly yellow/ reddish (level 5).

Solid-phase microextraction (SPME) and GC-MS analysis

The extraction and desorption method by HS-SPME was based on the method developed to leaf analysis of the Eugenia uniflora with few modifications..$^{30}$ In order to reproduce as close as possible the natural process of the odors emission that depends on the bark thickness and porosity, whole fruit and extraction room temperature were used. In further details, whole fruits were kept in a sealed glass vessel ( $26 \mathrm{~cm}$ length $\times 15 \mathrm{~cm}$ width $\times 15 \mathrm{~cm}$ height) maintained at room temperature about $25{ }^{\circ} \mathrm{C}$ during $8 \mathrm{~h}$ to saturation of the recipient atmosphere with volatile compounds emitted by mango fruit. Then, an SPME fiber (CAR/PDMS, $75 \mu \mathrm{m}$ ) was exposed for VOCs extraction in headspace mode during $12 \mathrm{~h}$ and stored at room temperature about $25^{\circ} \mathrm{C}$. A long period of $12 \mathrm{~h}$ was necessary to have the capture of minority and less volatile compounds guaranteed. The fiber was then removed from the sealed vial and inserted into the GC injector for thermal analytes desorption at $250^{\circ} \mathrm{C}$ for $3 \mathrm{~min}$ for GC-MS analysis. Before extraction, the fibers were conditioned in the injector following the manufacturer's instructions.

The GC-MS analysis was made using a Shimadzu GCMS-QP2010 Plus (Kyoto, Japan) with a $70 \mathrm{eV}$ electron impact ionization source. For analyte desorption/injection in the column, a splitless injector was used. The chromatograph was equipped with a Rxi-1 MS column (100\% dimethylpolysiloxane; $30 \mathrm{~m} \times 0.25 \mathrm{~mm}$ internal diameter $\times 0.25 \mu \mathrm{m}$, Restek, Bellefonte, USA). The oven temperature programming was as follows: $40{ }^{\circ} \mathrm{C}$ for $3 \mathrm{~min}$, increasing from $1{ }^{\circ} \mathrm{C} \mathrm{min}-1$ to 
$100{ }^{\circ} \mathrm{C}$, from $0.7^{\circ} \mathrm{C} \mathrm{min}-1$ to $125^{\circ} \mathrm{C}$, and from $8{ }^{\circ} \mathrm{C} \mathrm{min}^{-1}$ to $250^{\circ} \mathrm{C}$, sustained for $5 \mathrm{~min}$. A constant flow of carrier gas helium was maintained at $0.60 \mathrm{~mL} \mathrm{~min}^{-1}(15.4 \mathrm{kPa})$, at a constant linear speed of $27.9 \mathrm{~cm} \mathrm{~s}^{-1}$. The transfer line and ionization source temperature was $230{ }^{\circ} \mathrm{C}$.

The detected compounds were identified by comparing their experimental mass spectra resulting from the GC-MS acquisition with mass spectra from the Library (NIST 147 Database). The confirmation was carried out by comparison of the retention time of a $\mathrm{C}_{8}-\mathrm{C}_{24}$ analogous alkane series. Some compounds were confirmed by analytical standard (Table 1).

Table 1. Volatile chemical composition $(n=4)$ of different mango cultivars and two maturation stages (green and ripe). Means with different letters within a row are significantly different at $p<0.05$

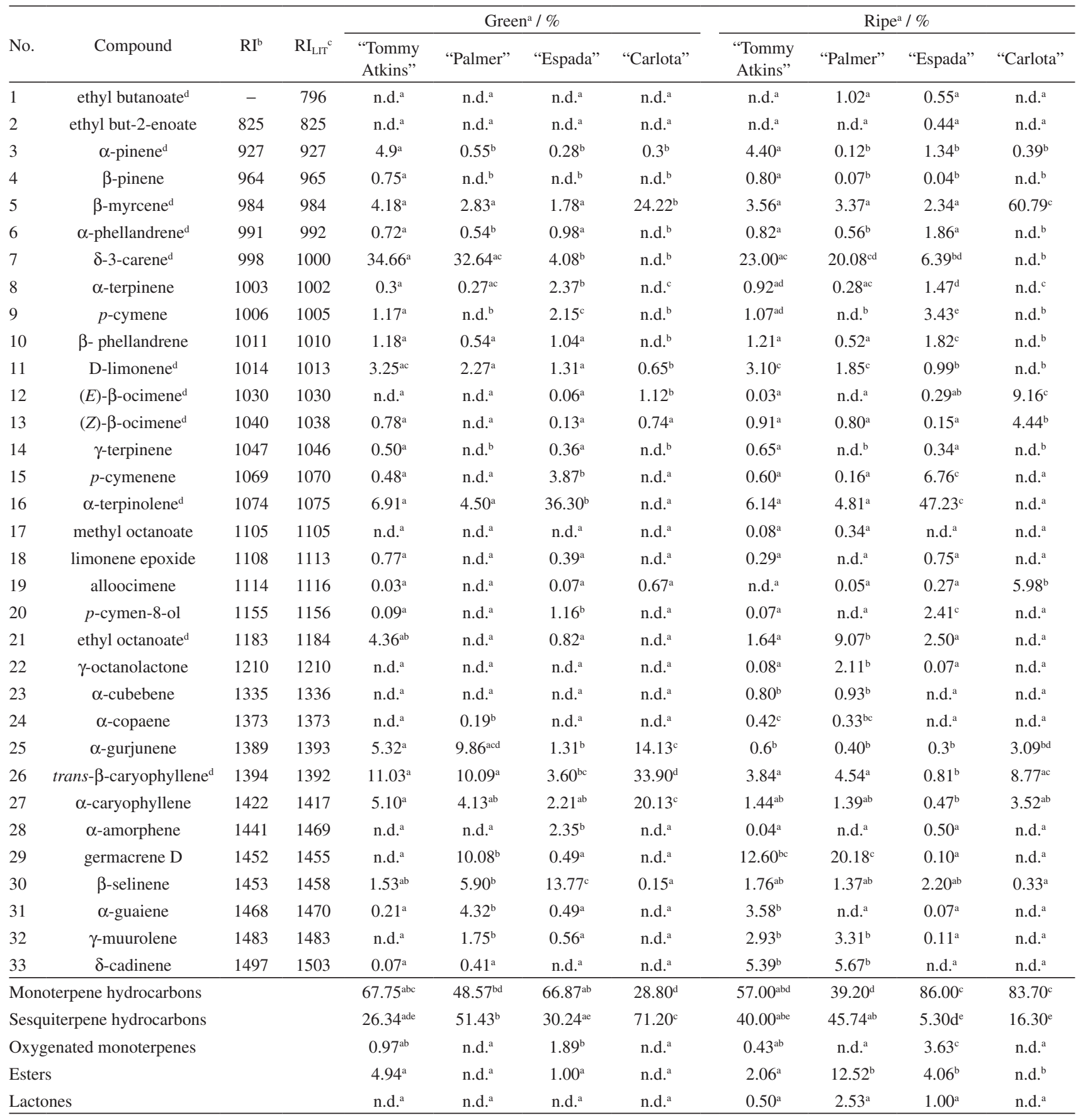

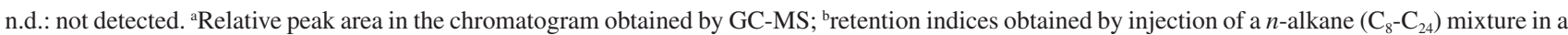
Rxi MS-1 capillary column; ' retention indices of compounds in a Rxi MS-1 or equivalent, according to the data provided by NIST database; identification was validated against mass spectrum and retention time of analytical standard. 


\section{Statistical analysis of the VOCs profile data}

Four fruits of each cultivar were analyzed by GC-MS at both ripening stages. The peak area for each identified compound was calculated using LabSolution software version 2.0 (Shimadzu). The relative peak areas were calculated according to the total peak areas in each sample as suggested in other previous works..$^{30,31}$ Statistical analyses was performed using Metaboanalyst 3.0 package. $^{32}$

Analysis of variance (ANOVA) and Tukey's test $(P<0.05)$ were carried out to assess the significant difference among the groups. Data used for multivariate analysis were a matrix of 33 compounds $\times 32$ samples of the four above mentioned mango varieties ("Tommy Atkins", "palmer", "espada" and "Carlota"), in green and ripe fruits. The values for the relative areas of the compounds in the sample were autoscaled ${ }^{33,34}$ and underwent principal component analysis (PCA) and hierarchical cluster analysis (HCA) associated with the heatmap.

\section{Results and Discussion}

The volatile compound profiles of four cultivars in the green and ripe stages were analyzed by HS-SPME/GC-MS to characterize and differentiate varieties and their ripening stages. Figure 1 shows the characteristic chromatograms of each mango variety in green and ripe stages. Note that the profiles are clearly different in the number of peaks as well as their abundances. Thirty-three volatile compounds were identified: 30 from varieties "Tommy Atkins", 29 from "espada", 25 from "palmer" and 10 from "Carlota". Each mango cultivar has different compounds as the most abundant. In addition, the most abundant compounds vary according to the degree of ripeness of the fruit. Table 1 shows the identified VOCs, their retention indices (RI) in the Rxi-1 MS capillary column, and the average relative composition $(n=4)$ of each compound in all the variety samples.

In this study, the majority of identified volatile compounds in the four mango varieties were monoterpene and sesquiterpene hydrocarbons in all ripening stages, although oxygenated monoterpenes, esters and lactones were also identified. In the varieties "Tommy Atkins", "palmer", "espada" and "Carlota" the percentage of identified compounds varied from 88.32 to $95.94 \%$ of the total area of peaks detected in the green fruit samples. The variation in the ripe stage samples ranged from 82.84 to $96.38 \%$.

Figure 2 shows the box plots of classes of compounds for four mango cultivars in green and ripe stages. During ripening, a tendency to a decrease in the percentage of monoterpene hydrocarbons and an increase in the percentage of sesquiterpenes were observed in the cultivar "Tommy Atkins", yet not statistically significant. On the other hand, an increase in the percentage of monoterpene hydrocarbons and a decrease in the percentage of sesquiterpenes were statistically significant for the varieties "espada" and "Carlota" $(p<0.05)$. For the cultivar "palmer", neither statistical difference nor a decrease in the percentage of monoterpenes and sesquiterpenes during ripening were evidenced. In the ripe stage, the percentage of monoterpene hydrocarbons in all the varieties was higher than the percentage of sesquiterpenes, except for the "palmer" variety.

It has been proposed that the aroma of different mango cultivars can be classified based on the prevalence of monoterpenes or sesquiterpenes. ${ }^{7}$ The terpene $\delta$-3-carene was the dominant compound of "Tommy Atkins" and "palmer" cultivars; $\alpha$-terpinolene was the major contributor to "espada", while $\beta$-myrcene was the major compound in "Carlota". Therefore, the four cultivars of this study belong to the group with the predominance of monoterpene hydrocarbons.

As regards the VOCs profile of different mango varieties, Canuto et $a l .{ }^{35}$ used SPME to identify 32 compounds in "Tommy Atkins" mangoes grown in the Vale do São Francisco in Pernambuco. Our study identified 19 of these compounds. The authors analyzed the VOCs profile of mangoes in green, ripening and ripe stages and thus identified the compounds associated with ripening such as ethyl esters and ethanol. Moreover, their results showed a decrease in the percentage of monoterpenes and an increase of sesquiterpenes during the ripening process. In another study, Lopes et al. ${ }^{20}$ applied the static headspace technique followed by GC-MS analysis to identify the VOCs emitted by 6 mango varieties including "Carlota", "espada" and "Tommy Atkins".

Sixteen out of the thirty-two compounds identified in this research were evaluated. Some of them, as $\delta$-3-carene, $\alpha$-pinene and $\beta$-myrcene are thought to have a greater influence on the aroma of mangoes based on the results obtained from aroma extract dilution analysis (AEDA) in gas chromatography-olfactometry (GC-O). Note that whole fruits were used to try to reproduce as close as possible the natural process of the odors emission that depends on the bark thickness and porosity. As peeled and sliced fruit do not have the diffusion process of the VOCs through the bark, to reproduce the natural odors emission was not possible. Thus, in addition to detect the majority of compounds reported in other studies using SPME or other extraction techniques, this method allows performing the monitoring without loss of the fruit sample. 
(a) Tommy Atkins (green)
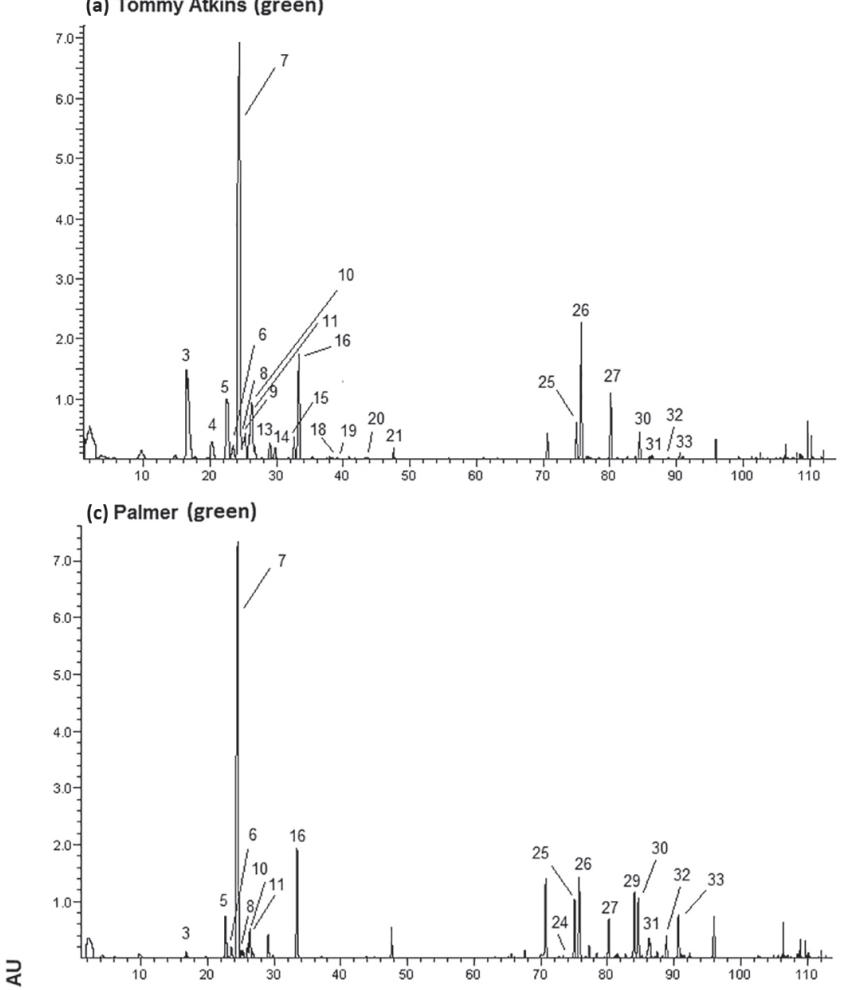

(e) Espada (green)

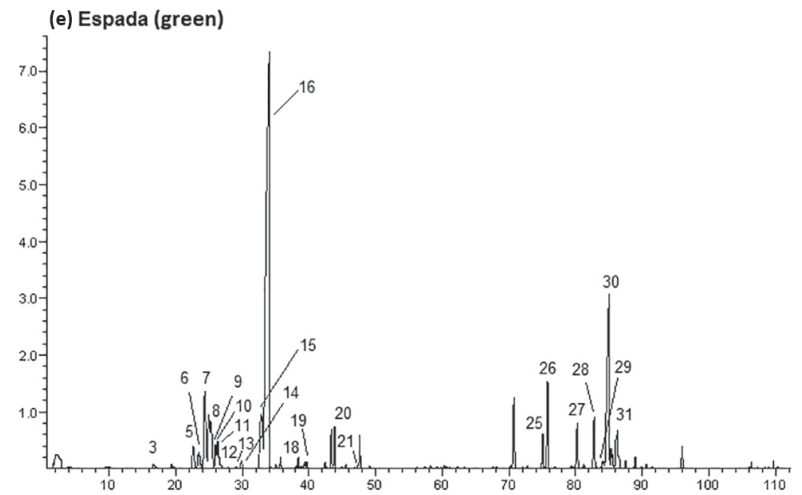

(g) Carlota (green)

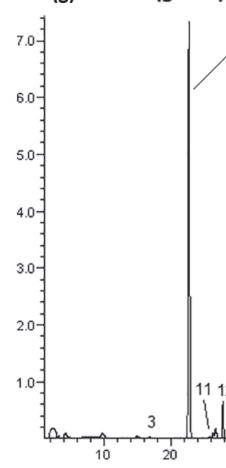

(b) Tommy Atkins (ripe)

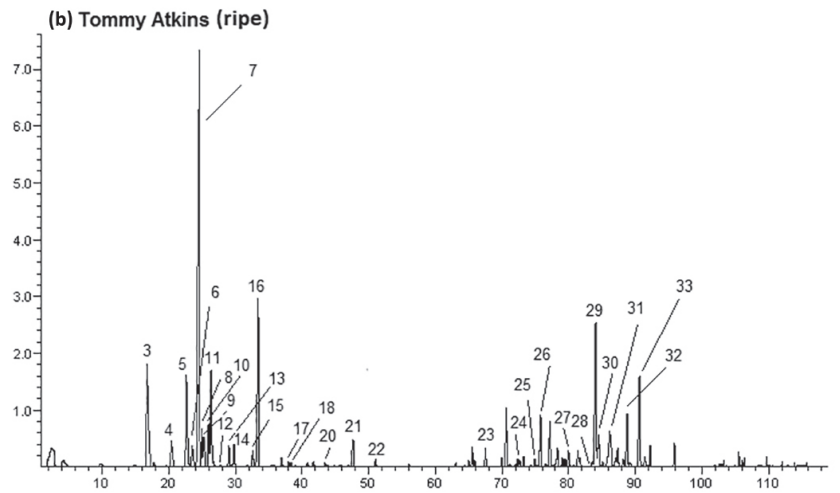

(d) Palmer (ripe)
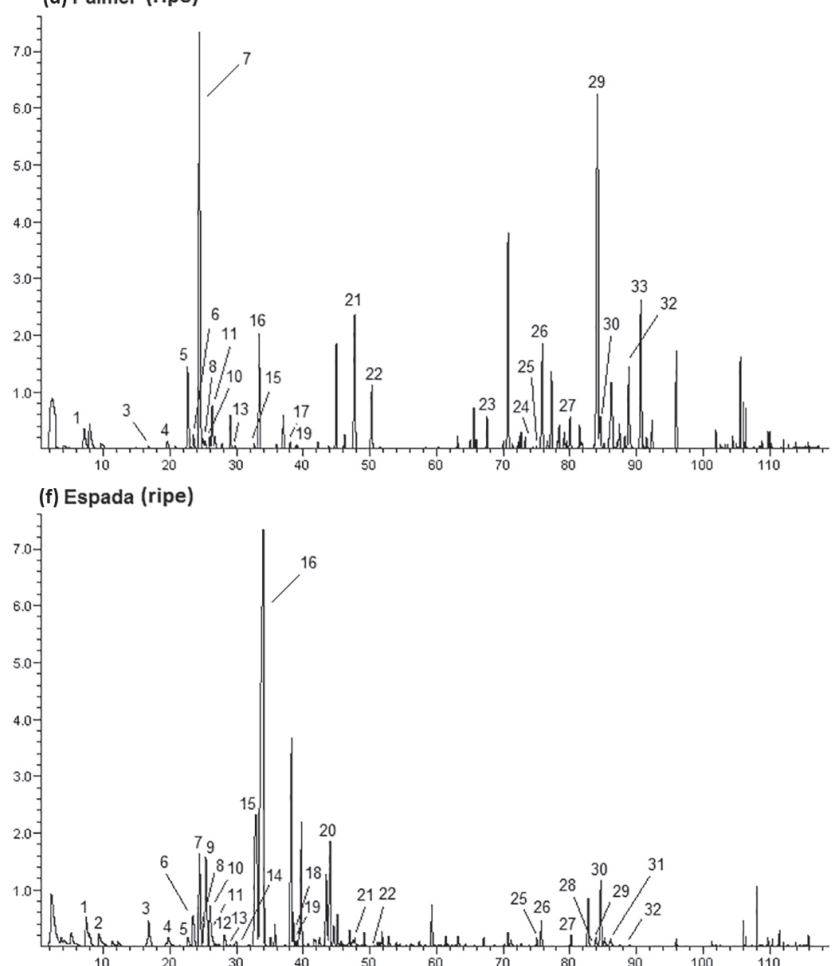

(h) Carlota (ripe)

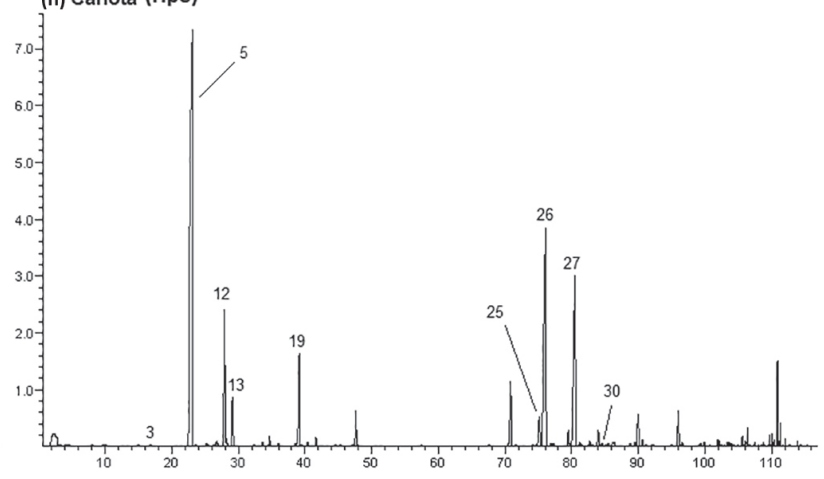

Figure 1. Profile comparison obtained by HS-SPME/GC-MS after VOCs analyses of four mango varieties in green and ripe stages: (a) "Tommy Atkins" green; (b) "Tommy Atkins" ripe; (c) "palmer" green; (d) "palmer" ripe; (e) "espada" green; (f) "espada" ripe; (g) "Carlota” green; (h) "Carlota" ripe (for identification of numbered peaks see Table 1).

So far, the study of Beaulieu and Lea ${ }^{36}$ was the only one that have assessed the VOCs profile of the cultivar "palmer". Using HS-SPME/GC-MS in fruits under different storage conditions allowed the identification of ten compounds, six of which were analyzed in our study. Some of these compounds have been reported in the literature..$^{7,15,17,28}$ 
(a) Monoterpene hydrocarbons

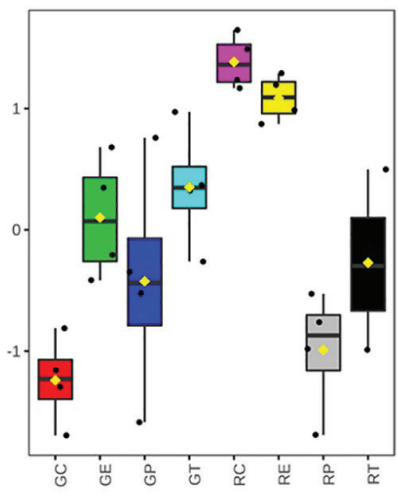

(b) Sesquiterpene hydrocarbons

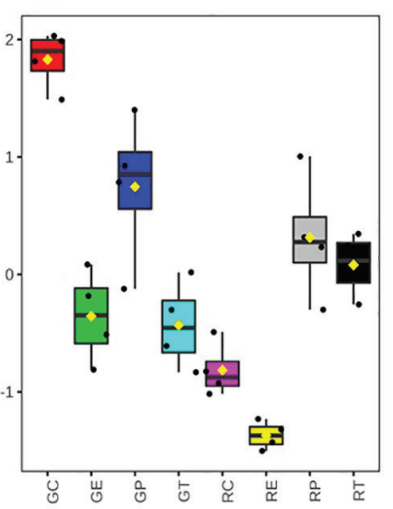

(c) Oxygenated monoterpenes

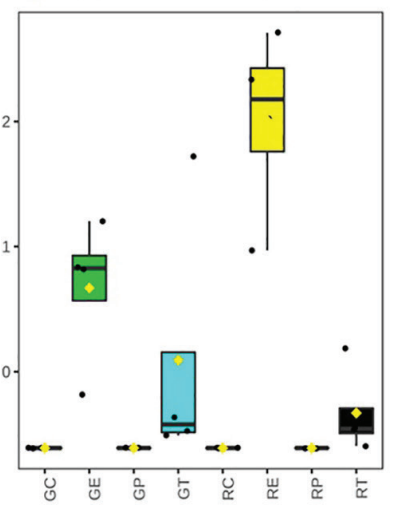

(d) Esters

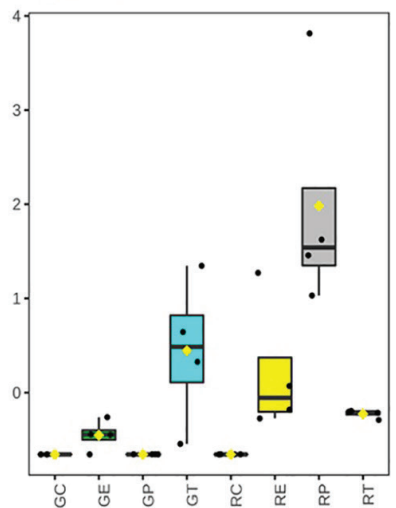

Figure 2. Box plots of classes of monoterpene hydrocarbons (a), sesquiterpenes hydrocarbons (b), oxygenated monoterpenes (c) and esters (d) compounds of the different mango varieties in green and ripe stages (RC: ripe "Carlota"; GC: green "Carlota"; RE: ripe "espada"; GE: green "espada"; RP: ripe "palmer"; GP: green "palmer"; RT: ripe "Tommy Atkins"; GT: green "Tommy Atkins"). In the box plot, Y axis represents normalized concentrations of the compounds as quartile for each sample group. The range of the vertical scale is from the minimum to the maximum value of the selected group, or, to the highest or lowest of the displayed reference points, median, and $95 \%$ confidence interval.

However, there were some differences in the VOCs we identified. These differences may be related to several factors, among which the extraction technique used, extraction conditions, type of fiber in the SPME, and the chromatography column used in the GC.

The variety and ripening stage characterization and differentiation was based on the volatile compound profile followed by a multivariate HCA. Figure 3 shows the sample and volatile compounds dendogram associated to the VOCs profile heatmap. The simultaneous use of a dendogram and a heatmap improves the visualization of the relationships among variables and samples. ${ }^{37}$

The four mango varieties and their ripening stages were fully discriminated by the HCA as shown in Figure 3. The varieties "Carlota" and "espada" formed distinctive clusters while the varieties "Tommy Atkins" and "palmer" presented a lower clustering tendency. Concerning the "Tommy Atkins" and "palmer" varieties, the compounds responsible for the discrimination of their VOCs profiles as observed in the HCA could be explained by the fact that both varieties have the same progenitor, namely the cultivar "Haden". These three varieties were developed in Florida (USA) and have different characteristics due to crossovers between Indian and South Asiatic cultivars under southern Florida's climatic conditions. ${ }^{38}$

The heatmap shows the influence of each compound on the four varieties and their ripening stages. "Carlota" green mangoes had a higher concentration of $\beta$-myrcene, $\alpha$-gurjunene, trans- $\beta$-caryophyllene and $\alpha$-caryophyllene, while the amount of $(E)$ - $\beta$-ocimene, $(Z)-\beta$-ocimene and alloocimene was higher in ripe "Carlota" mangoes. The compounds $\alpha$-terpinolene, $\beta$-selinene and $\alpha$-amorphene were characteristic of the ripe stage of the cultivar "espada" in its green stage, whereas $\alpha$-terpinolene, $p$-cymenene, $p$-cimen-8-ol, $p$-cymene, $\alpha$-phellandrene and $\beta$-phellandrene characterized the ripe stage. The cultivar "palmer" in its green stage was characterized by $\delta$-3-carene, $\alpha$-gurjunene and $\alpha$-guaiene which had great influence on the discrimination of green samples. It must be pointed out that in the ripe stage ethyl butanoate, methyl octanoate, ethyl octanoate, $\gamma$-octanolactone, $\alpha$-cubebene, $\delta$-cadinene, $\alpha$-copaene, germacrene $\mathrm{D}$ and $\gamma$-muuroleno were the compounds with more influence on the discrimination of that stage. Esters are the main markers of ripe "palmer" mangoes. The prevalent compounds in green "Tommy Atkins" mangoes were $\delta$ - 3 -carene, $\alpha$-pinene, $\beta$-pinene and D-limonene, while the ripe stage was characterized by $\alpha$-cubebene, $\delta$-cadinene, $\alpha$-copaene, germacrene D and $\gamma$-muurolene.

The identification of VOCs emitted by different green and ripe mango varieties might explain the preference of some pest insects, such as the fruit flies, for some varieties and ripening stages. ${ }^{39}$ The Ceratitis capitata and Anastrepha obliqua, for example, are the main fruit fly species to cause damage in mango cultures by oviposition in the fruits. ${ }^{40}$ There are some varieties, however, whose peel produces a resin which is less attractive to fruit flies probably due to high egg mortality in the fruits. ${ }^{41}$ Moreover, a relationship could be observed between the VOCs profile of the four mango varieties and their susceptibility or resistance to fruit flies. ${ }^{42}$ The host plant selection of phytophagous fly females consists of a chain of three different stimuli: the VOCs emitted by the plant, the visual stimulus, and the non-volatile compounds present in the fruit (nutrients and toxic substances to insect eggs). ${ }^{43} \mathrm{~A}$ feasible alternative to reduce damages caused by fruit flies would be growing mango varieties that are less attractive to this pest. 


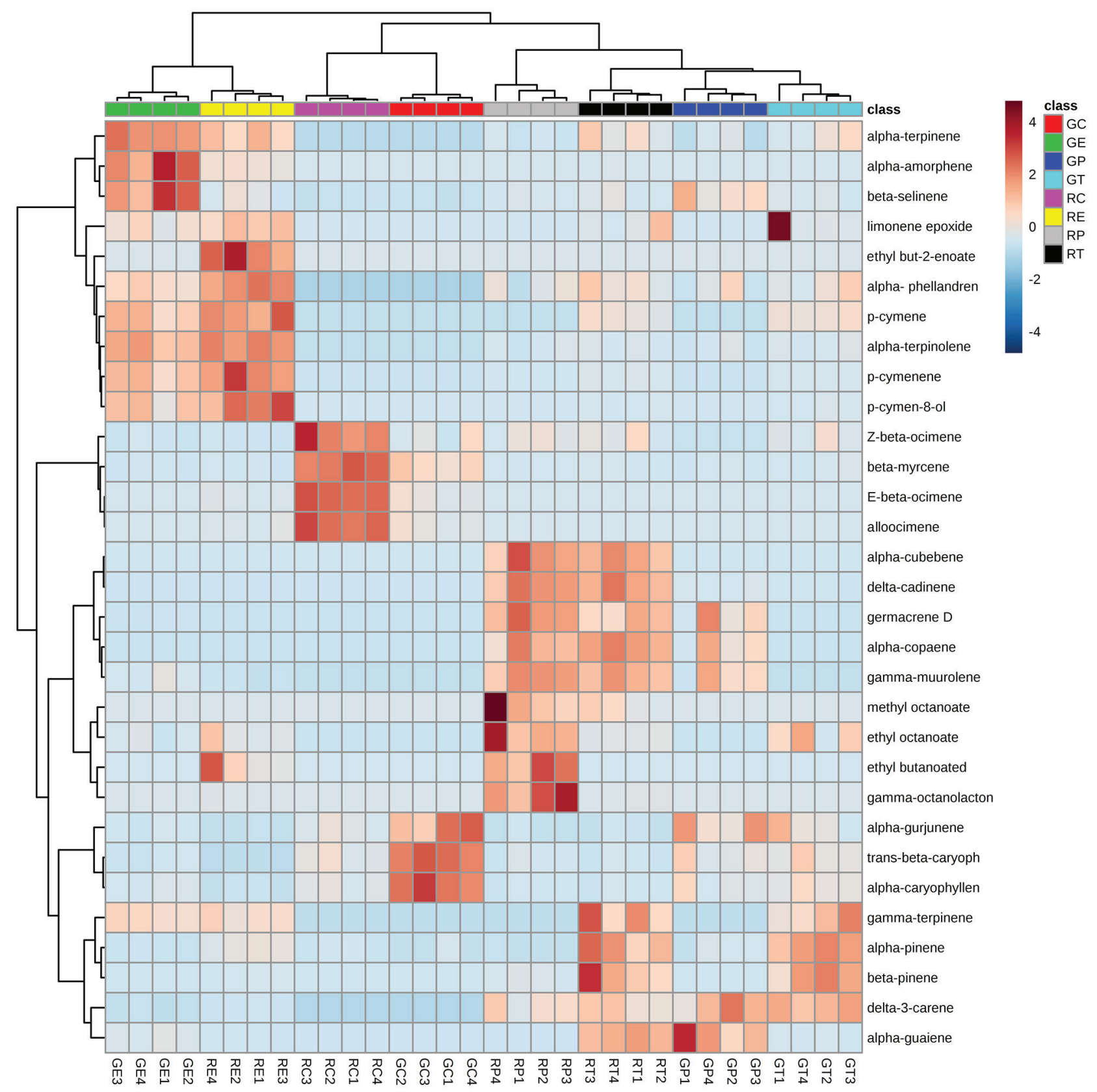

Figure 3. Dendogram associated to heatmap of volatile compounds identified in the four mango varieties in green and ripe stages (RC: ripe "Carlota"; GC: green "Carlota"; RE: ripe "espada"; GE: green "espada"; RP: ripe "palmer”; GP: green "palmer”; RT: ripe "Tommy Atkins”; GT: green “Tommy Atkins").

The PCA was applied to identify the main compounds responsible for the sample clustering of the four mango varieties and their ripening stages. ${ }^{44}$ Figure 4 shows that the PCA resulted in 8 different clusters. The volatile compounds that discriminate sample clusters can be seen in Figure 5. It should be noted that the green fruit samples tended to be in the center, whereas the vectors that represents the compound weights for the class were smaller. "Tommy Atkins" and "palmer" displayed higher variances between green and ripe stages which might be explained by the higher weight of esters in both varieties.
In terms of variation of just terpenes and sesquiterpenes, "espada" and "Carlota" presented lower variances between green and ripe stages.

The PCA and HCA, as chemometric tools, allowed for a wider evaluation of the VOCs profile of each mango variety as well as for the discrimination of samples. The same analysis has been carried out by Benevides et al. ${ }^{45}$ who used PCA and HCA to discriminate "Tommy Atkins", "espada" and "rosa" varieties through the 23 VOCs identified by HS-SPME/GC-MS.

Andrade et al. ${ }^{46}$ analyzed the VOCs of 15 mango 


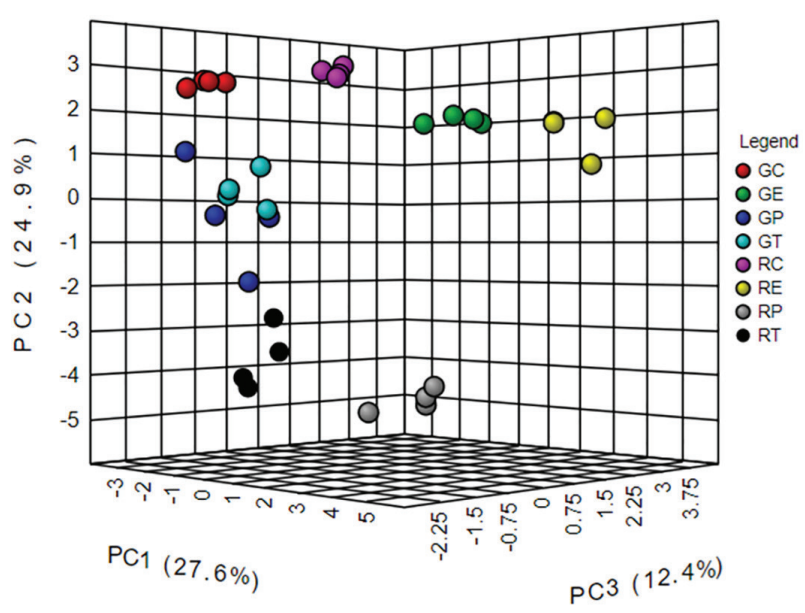

Figure 4. $\mathrm{PC} 1$ versus $\mathrm{PC} 2$ score graph of four mango varieties in their green and ripe stages (RC: ripe "Carlota"; GC: green "Carlota"; RE: ripe "espada"; GE: green "espada"; RP: ripe "palmer"; GP: green "palmer"; RT: ripe "Tommy Atkins"; GT: green "Tommy Atkins").

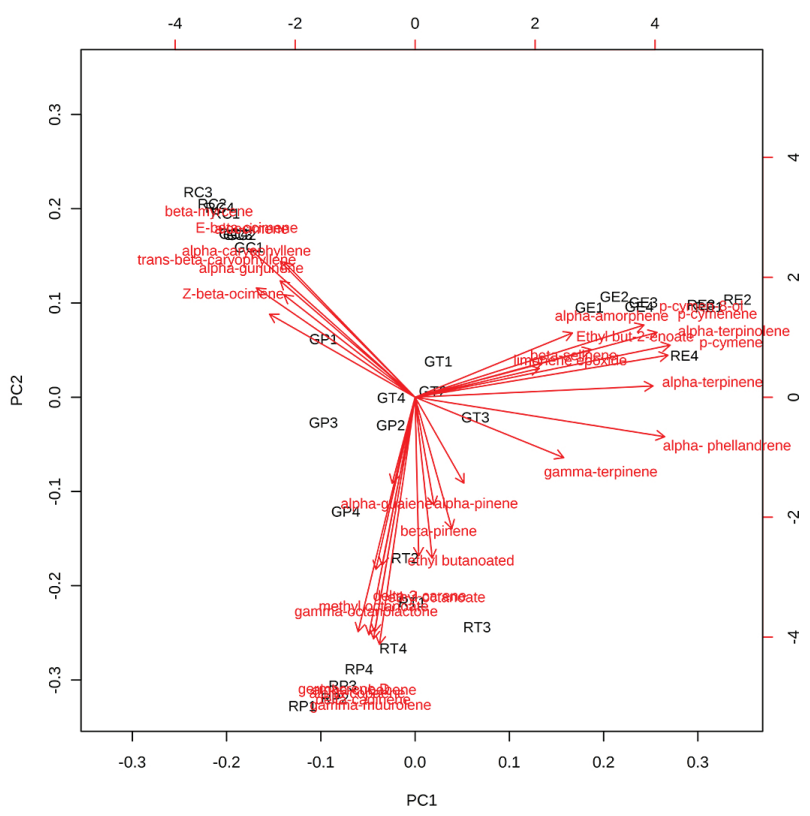

Figure 5. Loadings plot ( $\mathrm{PC} 1$ versus $\mathrm{PC} 2$ ) of the volatile organic compounds responsible by discrimination of the four mango varieties and their green and ripe stages (RC: ripe "Carlota"; GC: green "Carlota"; RE: ripe "espada"; GE: green "espada"; RP: ripe "palmer"; GP: green "palmer"; RT: ripe "Tommy Atkins"; GT: green "Tommy Atkins").

varieties produced in Brazil and classified them in three groups based on the prevalent compound $\alpha$-terpinolene, $\delta$-3-carene or myrcene. The results show that the cultivar "espada" has higher amounts of $\alpha$-terpinolene, whereas the cultivar "Carlota" has higher amounts of myrcene. Terpene $\delta$-3-carene was the prevalent compound in the varieties "Tommy Atkins" and "palmer". Other studies reported similar results regarding the varieties "Tommy Atkins", "espada" and "palmer". ${ }^{20,36,47}$ Nonetheless, these results are not aligned to those obtained by Andrade et al., ${ }^{46}$ who found that $\alpha$-terpinolene and myrcene were prevalent in the varieties "Carlota" and "espada", respectively. The differences observed might be due to various factors, such as the geographic origin of the fruits, part of fruit analyzed (pulp with or without peel), subjective assessment of the fruit ripening stage, and extraction technique used..$^{12,14}$

Besides, the volatile components that provide fruit aroma are one of the most important quality indicators. The volatiles profile has already been used for the discrimination and classification of several mango cultivars from China, ${ }^{48}$ Australia ${ }^{49}$ and different continents. ${ }^{50}$

The ripening stage assessment of mangoes is the major step in the selection of fruits for exportation. If they are harvested in the green stage a precocious ripening occurs resulting in low-quality fruits. Fruit sorting for commercialization includes the assessment of the fruit ripening stage through titratable acidity, amount of total soluble sugars and carotenoids, besides weight, firmness and color. Most of these analyses destroy the fruits, are time-consuming, and the accuracy of the results regarding the ripening stage is not always ensured. ${ }^{51}$ This research shows that profile analysis of volatile compounds is a useful method to differentiate the green and ripe stages of the varieties "Tommy Atkins", "palmer", "espada" and "Carlota". Some volatile compounds are ripening markers of specific mango varieties and might be used in fruit sorting for commercialization. Gas chromatography and electronic nose, for example, were used to detect volatile compounds associated with mango ripening stages, thus allowing accurate discrimination of ripening stage as well as an estimate of the best time for harvesting. ${ }^{10}$

\section{Conclusions}

This study might prove useful for mango agribusiness as it shows the characteristic VOCs profile of four mango varieties "Tommy Atkins", "palmer", "espada" and "Carlota" in their green and ripe stages. The VOCs profile analysis through HS-SPME/GC-MS associated with HCA and PCA multivariate data analysis enabled this research to discriminate mango varieties and differentiate ripening stages. The volatile compounds that characterize the ripening stages of the four mango varieties assessed in this study might be used in electronic noses to improve the sorting efficiency and thus the quality control of export fruits that meet the market requirements.

\section{Acknowledgments}

The authors acknowledge Bahia State Research Support Foundation (FAPESB) for financial support, Coordination for the Improvement of Higher Education Personnel 
(CAPES) for the scholarship granted to P. R. R. Mesquita and National Council for Scientific and Technological Development (CNPq) for the fellowship (140743/2013-8) supported to F. N. dos Santos.

\section{Author Contributions}

Conceptualization was done by P. R. R. Mesquita, A. S. Nascimento, F. M. Rodrigues; data curation by P. R. R. Mesquita, F. N. Santos, F. M. Rodrigues; formal analysis by P. R. R. Mesquita, L. C. Pena, C. C. Oliveira; funding acquisition by J. T. Magalhães-Junior, A. S. Nascimento, F. M. Rodrigues; investigation by P. R. R. Mesquita, J. T. Magalhães-Junior; project administration by F. M. Rodrigues; resources by A. S. Nascimento, F. M. Rodrigues; validation by P. R. R. Mesquita, L. C. Pena; visualization by L. C. Pena, C. C. Oliveira, J. T. MagalhãesJunior, A. S. Nascimento; writing original draft by P. R. R. Mesquita, F. N. Santos; writing-review and editing by P. R. R. Mesquita, F. N. Santos, F. M. Rodrigues.

\section{References}

1. Ornelas-Paz, J. J.; Yahia, E. M.; Gardea, A.; Am. J. Agric. Biol. Sci. 2010, 5, 301.

2. Chauhan, O. P.; Raju, P. S.; Bawa, A. S. In Handbook of Fruit and Vegetable Flavors; Hui, Y. H., ed.; Wiley: Hoboken, USA, 2010, p. 319.

3. Anuário Brasileiro de Horti\&Fruti 2019; Beling, R. R., ed.; Editora Gazeta: Santa Cruz do Sul, Brazil, 2018, p. 73. Available at http://www.editoragazeta.com.br/produto/anuario-brasileirode-horti-fruti-2019/, accessed in February 2020.

4. Mouco, M. A. C.; Lima Neto, F. P.; A Mangueira no Vale do São Francisco; Boletim Frutícola/Toda Fruta: Jaboticabal, Brazil, 2018. Available at https://www.todafruta.com.br/wp-content/ uploads/2018/06/MANGA.pdf, accessed in February 2020.

5. de Oliveira, A. R.; Moreira, A. N.; Teixeira, A. H. C.; Paranhos, B. J.; Santos, C. A. F.; de Faria, C. M. B.; Silva, D. J.; Bastos, D. C.; Batista, D. C.; de Lima Neto, F. P.; Angelotti, F.; da Costa, J. G.; de Alencar, J. A.; dos Anjos, J. B.; Oliveira, J. E. M.; Araújo, J. L. P.; Pinto, J. M.; de Assis, J. S.; Bassoi, L. H.; de Moura, M. S. B.; Calgaro, M.; Braga, M. B.; Mouco, M. A. C.; da Silva, P. C. G.; Correia, R. C.; Cunha, T. J. F.; Petrere, V. G.; Simões, W. L.; Cultivo da Mangueira; $2^{\text {nd }}$ ed.; Embrapa Semiárido: Petrolina, Brazil, 2010. Available at https://www. infoteca.cnptia.embrapa.br/infoteca/bitstream/doc/884451/1/ CultivodaMangueira.pdf, accessed in February 2020.

6. Perosa, J. M. Y.; Pierre, F. C.; Rev. Bras. Frutic. 2002, 24, 381.

7. Pino, J. A.; Mesa, J.; Muñoz, Y.; Martí, M. P.; Marbot, R.; J. Agric. Food Chem. 2005, 53, 2213.

8. Pino, J. A.; Mesa, J.; Flavour Fragrance J. 2006, 21, 207.
9. Quijano, C. E.; Salamanca, G.; Pino, J. A.; Flavour Fragrance J. 2007, 22, 401.

10. Lebrun, M.; Plotto, A.; Goodner, K.; Ducamp, M.-N.; Baldwin, E.; Postharvest Biol. Technol. 2008, 48, 122.

11. Pandit, S. S.; Kulkarni, R. S.; Chidley, H. G.; Giri, A. P.; Pujari, K. H.; Kollner, T. G.; Degenhardt, J.; Gershenzon, J.; Gupta, V. S.; J. Sci. Food Agric. 2009, 89, 2071.

12. Kulkarni, R. S.; Chidley, H. G.; Pujari, K. H.; Giri, A. P.; Gupta, V. S.; Food Chem. 2012, 130, 58.

13. Lalel, H. J. D.; Singh, Z.; Tan, S. C.; J. Hortic. Sci. Biotechnol. 2003, 78, 131.

14. Chidley, H. G.; Kulkarni, R. S.; Pujari, K. H.; Giri, A. P.; Gupta, V. S.; Food Chem. 2013, 136, 585.

15. Canuto, K. M.; Souza Neto, M. A.; Garruti, D. S.; Lima, M. A. C.; Quim. Nova 2010, 33, 1535.

16. Torres, J. D.; Talens, P.; Carot, J. M.; Chiralt, A.; Escriche, I.; Food Chem. 2007, 101, 219.

17. Pandit, S. S.; Chidley, H. G.; Kulkami, R. S.; Pujari, K. H.; Giri, A. P.; Gupta, V. S.; Food Chem. 2009, 114, 363.

18. Ollé, D.; Baumer, R. L.; Bayonove, C. L.; Lozano, Y. F.; Sznaper, C.; Brillout, J.-M.; J. Agric. Food Chem. 1998, 46, 1094.

19. MacLeod, A. J.; Snyder, C. H.; J. Agric. Food Chem. 1985, 33, 380.

20. Lopes, D. C.; Fraga, S. R.; Rezende, C. M.; Quim. Nova 1999, 22,31 .

21. Gebara, S. S.; Ferreira, W. O.; Ré-Poppi, N.; Simionatto, E.; Carasek, E.; Food Chem. 2011, 127, 689.

22. Bojko, B.; Cudjoe, E.; Gómez-Ríos, G. A.; Gorynski, K.; Jiang, R.; Reyes-Garcés, N.; Risticevic, S.; Silva, E. A. S.; Togunde, O.; Vuckovic, D.; Pawliszyn, J.; Anal. Chim. Acta 2012, 750, 132.

23. Sousa, E. T.; Rodrigues, F. M.; Martins, C. C.; Oliveira, F. S.; Pereira, P. A. P.; de Andrade, J. B.; Microchem. J. 2006, 82, 142.

24. Passinho-Soares, H. C.; Meira, P. R.; David, J. P.; Mesquita, P. R. R.; do Vale, A. E.; Rodrigues, F. M.; Pereira, P. A. P.; de Santana, J. R. F.; de Oliveira, F. S.; de Andrade, J. B.; David, J. M.; Molecules 2013, 18, 10320.

25. Cappelaro, E. A.; Yariwake, J. H.; Quim. Nova 2015, 38, 427.

26. García, Y. M.; Rufini, J. C. M.; Campos, M. P.; Guedes, M. N. S.; Augusti, R.; Melo, J. O. F.; J. Braz. Chem. Soc. 2019, 30, 247.

27. Kataoka, H.; Lord, H. L.; Pawliszyn, J.; J. Chromatogr. A 2000, $880,35$.

28. Valente, A. L. P.; Augusto, F.; Quim. Nova 2000, 23, 523.

29. Assis, J. S.; Lima, M. A. C.; Produção Integrada de Manga: Manejo Pós-Colheita e Rastreabilidade; Circular Técnica No. 89; Embrapa Semi-Árido: Petrolina, Brazil, 2008. Available at https://www.embrapa.br/en/busca-de-publicacoes/-/ publicacao/143831/producao-integrada-de-manga-manejo-poscolheita-e-rastreabilidade, accessed in February, 2020. 
30. Mesquita, P. R. R.; Nunes, E. C.; Santos, F. N.; Bastos, L. P.; Costa, M. A. P. C.; Rodrigues, F. M.; de Andrade, J. B.; Microchem. J. 2017, 130, 79.

31. Matsushita, T.; Zhao, J. J.; Igura, N.; Shimoda, M.; J. Sci. Food Agric. 2018, 98, 2989.

32. Xia, J.; Sinelnikov, I. V.; Han, B.; Wishart, D. S.; Nucleic Acids Res. 2015, 43, W251.

33. Araujo, P. W.; Brereton, R. G.; TrAC, Trends Anal. Chem. 1996, $15,26$.

34. Ferreira, M. M. C.; Quimiometria - Conceitos, Métodos e Aplicações; Editora da Unicamp: Campinas, Brazil, 2015.

35. Canuto, K. M.; Souza Neto, M. A.; Garruti, D. S.; Quim. Nova 2009, 32, 2377.

36. Beaulieu, J. C.; Lea, J. M.; Postharvest Biol. Technol. 2003, 30, 15.

37. Ivaniservic, J.; Benton, H. P.; Rinehart, D.; Epstein, A.; Kurczy, M. E.; Boska, M. D.; Gendelman, H. E.; Siuzdak, G.; Metabolomics 2015, 11, 1029.

38. Schnell, R. J.; Brown, J. S.; Olano, C. T.; Meerow, A. W.; Campbell, R. J.; Kuhn, D. N.; J. Am. Soc. Hortic. Sci. 2006, 131,214

39. Jayanthi, P. D. K.; Woodcock, C. M.; Caulfield, J.; Birkett, M. A.; Bruce, T. J.; J. Chem. Ecol. 2012, 38, 361.

40. de Sá, R. F.; Castellani, M. A.; Nascimento, A. S.; Brandão, M. H. S. T.; Silva, A. N.; Pérez-Maluf, R.; Bragantia 2008, 67, 401.
41. Joel, D. M.; J. Exp. Bot. 1980, 31, 1707.

42. Aluja, M.; Arredondo, J.; Díaz-Fleischer, F.; Birke, A.; Rull, J.; Niogret, J.; Epsky, N.; J. Econ. Entomol. 2014, 107, 375.

43. Gripenberg, S.; Mayhew, P. J.; Parnell, M.; Roslin, T.; Ecol. Lett. 2010, 13, 383.

44. Bro, R.; Smilde, A. K.; Anal. Methods 2014, 6, 2812.

45. Benevides, C. M. J.; Bezerra, M. A.; Pereira, P. A. P.; de Andrade, J. B.; Am. J. Anal. Chem. 2014, 5, 157.

46. Andrade, E. H. A.; Maia, J. G. S.; Zoghbi, M. G. B.; J. Food Compos. Anal. 2000, 13, 27.

47. Franco, M. R. B.; Rodriguez-Amaya, D.; Lanças, F. M.; Ciênc. Tecnol. Aliment. 2004, 24, 165.

48. Ma, X.-W.; Su, M.-Q.; Wu, H.-X.; Zhou, Y.-G.; Wang, S.-B.; Molecules 2018, 23, 1480.

49. San, A. T.; Joyce, D. C.; Hofman, P. J.; Macnish, A. J.; Webb, R. I.; Matovic, N. J.; Williams, C. M.; de Voss, J. J.; Wong, S. H.; Smyth, H. E.; Food Chem. 2016, 221, 613.

50. Li, L.; Mao, X.-W.; Zhan, R.-L.; Wu, H.-X.; Yao, Q.-S.; Xu, W.-T.; Luo, C.; Zhou, Y.-G.; Liang, Q.-Z.; Wang, S.-B.; PLoS One 2017, 12, e0187487.

51. Crisosto, C. H.; Postharvest News Inform. 1994, 5, 65.

Submitted: July 19, 2019

Published online: February 17, 2020 